\title{
Prediksi Customer Churn Berbasis Adaptive Neuro Fuzzy Inference System
}

\author{
Yayak Kartika Sari $^{1}$, Kusrini $^{2}$, Ferry Wahyu Wibowo $^{3}$ \\ 1,2,3 Teknik Informatika, Fakultas Teknik, Universitas Amikom Yogyakarta \\ E-mail: *11yayakkartikasari93132042@ gmail.com, 2 kusrini@amikom.ac.id, 3
}

ferry.w@amikom.ac.id

\begin{abstract}
Abstrak - Customer Churn adalah pelanggan yang berhenti berlangganan dan pindah pada perusahaan lain, karena berbagai faktor. Customer churn merupakan masalah yang sangat penting yang harus dihadaapi oleh perusahaan karena berhentinya pelanggan akan berdampak pada retensi perusahaan. Oleh sebab itu, dibuatkan sistem prediksi customer churn untuk mengetahui tingkat pelanggan yang churn, apabila customer churn dapat diketahui terlebih dahulu, maka akan menguntungkan bagi pihak CRM untuk mengatur strategi-strategi mencegah pelanggan yang melakukan churn. Untuk menentukan prediksi customer churn menggunakan teknik data mining dengan algoritma ANFIS. Algoritma ANFIS merupakan gabungan antara jaringan syaraf tiruan dengan fuzzy inference system. Model prediksi yang dibangun dengan metode ANFIS menggunakan pembelajaran alur maju dan pembelajaran alur mundur, sehingga untuk melakukan prediksi dibutuhkan nilai parameter fuzzy baru yang diperoleh dari proses pelatihan. Setelah nilai parameter fuzzy baru didapatkan, maka akan dilakukan tahap pengujian. Pada tahap pengujian dilakukan dengan proses pembelajaran maju untuk mendapatkan nilai prediksinya, sehingga pada prosesnya nilai prediksi yang berupa angka dan status prediksi. Pelatihan dan pengujian ANFIS untuk semua produk menghasilkan perbandingan nilai error rata-rata pelatihan sebesar 8,316\%.
\end{abstract}

Kata Kunci - Data Mining, ANFIS, CRM, Customer Churn.

\begin{abstract}
Customer Churn is a customer who unsubscribes and moves to another ISP, due to various factors. Customer churn is a very important issue that should be faced by the company because the cessation of customers will impact on corporate retention. Therefore, customer churn prediction system is made to know the level of customer churn, if customer churn can be known in advance, it will be advantageous for CRM to arrange strategies to prevent customers who do churn. To determine customer churn prediction using data mining techniques with ANFIS algorithm. ANFIS algorithm is a combination of artificial neural network with fuzzy inference system. Predictive models built with the ANFIS method use advanced groove learning and retrograde learning, so to make predictions it takes the value of new fuzzy parameters obtained from the training process. After the new fuzzy parameter values are obtained, the test phase will be performed. In the testing phase is done by the process of advanced learning to get predictive value, so that in the process predictive value in the form of numbers and prediction status. ANFIS training and testing for all products resulted in comparison of the average error rate of training of $8.316 \%$
\end{abstract}

Keywords - Data Mining, ANFIS, CRM, Customer Churn.

\section{PENDAHULUAN}

Perkembangan internet saat ini menjadi kebutuhan yang sangat penting bagi masyarakat. Tidak hanya sebagai sumber informasi tetapi bisa menjadi sarana pendukung kegiatan ekonomis dan hiburan. Menurut data www.internetworldstats.com, pengguna internet di Indonesia saat ini mencapai 132,7 juta jiwa dari total populasi sebesar 263 juta jiwa. Dengan perkembangan internet yang semakin luas saat ini, membuat penyedia jasa layanan internet menjadi semakin banyak dan berkembang, terutama di daerah kediri. Penyedia jasa layanan internet di daerah kediri yaitu PT. Telekomunikasi, Biznet, PT. Indosat M2, Primadona Net, CV. Global Media Data, dan lain-lain. 
Dari semua penyedia jasa layanan internet di Kediri memberikan penawaran-penawaran yang sangat menarik untuk meningkatkan pelanggan. Hal itu menjadi salah satu faktor penyebab terjadinya menurunnya pelanggan internet pada perusahaan XYZ disebabkan karena churn. Customer Churn atau turun naiknya pelanggan didefinisikan sebagai hilangnya pelanggan karena berpindah ke layanan lain.[1] Hal ini menjadi isu penting yang merupakan salah satu tantangan utama oleh perusahaan XYZ yang harus dihadapi, karena untuk memperoleh pelanggan baru memerlukan biaya 10 kali lipat lebih mahal dibandingkan biaya untuk mempertahankan pelanggan yang ada. Mahalnya untuk memperoleh pelanggan baru tentunya perusahaan lebih memilih mempertahankan pelanggan. Selain itu, terjadinya customer churn akan berdampak penurunan revenue perusahaan.[2] Maka dari itu, untuk mencegah terjadinya customer churn pada perusahaan XYZ maka dibutuhkanlah prediksi customer churn, agar perusahaan XYZ dapat mengatur strategi yang dapat mencegah customer churn di perusahaan XYZ.

Teknik yang digunakan untuk memprediksi adalan data mining. Data mining merupakan serangkaian proses untuk menggali nilai tambah dari suatu kumpulan data berupa pengetahuan yang selama ini tidak diketahui secara manual.[3] Sistem prediksi yang telah banyak diteliti antara lain analisis prediksi churn menggunakan metode logistic regression dan algoritma decision tree[4], prediksi customer churn menggunakan algoritma fuzzy iterative dichotomiser 3[2], IG-KNN untuk prediksi customer churn telekomunikasi, penggunaan deep learning untuk prediksi churn pada jaringan telekomunikasi mobile[5]. Tetapi untuk penelitian ini menggunakan metode metode ANFIS (Adaptive Neuro Fuzzy Inference System).

ANFIS merupakan gabungan dua sistem yaitu neural network dan fuzzy logic. Sistem saraf tiruan memberikan kemudahkan dalam mengklasifikasikan suatu objek. Berdasarkan masukan sistem, Fuzzy logic merupakan pemakaian fungsi keanggotaan untuk menentukan seberapa besar suatu predikat memenuhi suatu fungsi yang dinyatakan kedalam "if - then" yang memberi kemudahan dengan tidak memerlukan analisis matematik untuk pemodelan.[6]

Pokok permasalahan dari penelitian ini adalah penggunaan metode ANFIS untuk memprediksi customer churn di perusahaan XYZ Kediri. Sebagai masukannya, menggunakan data time series selama 2 tahun dengan variabel jumlah data status pelanggan dan data keluhan. Diharapkan dengan menggunakan ANFIS, sistem prediksi untuk customer curn dapat dilakukan dengan baik.

\section{METODE PENELITIAN}

Dalam penelitian ini, terdiri dari beberapa tahapan yang diawali dengan melakukan Studi literatur, pengumpulan data, penerapan algoritma ANFIS. Alur penelitian ditunjukkan oleh gambar 1 .

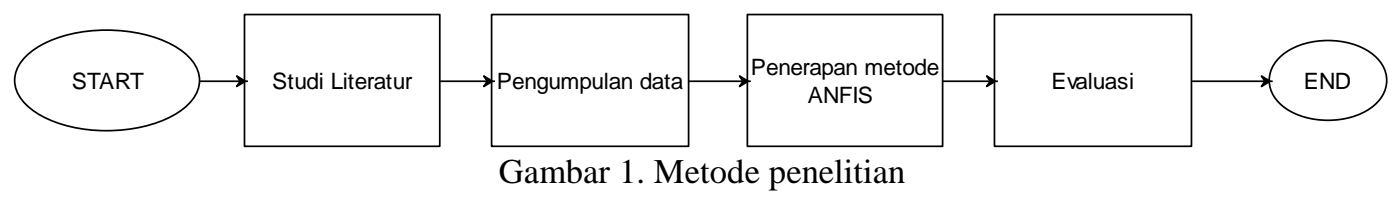

\subsection{Studi Literatur}

Metode melalui studi literature yang bertujuan mendapatkan pengetahuan dari penelitian yang akan dilakukan. Studi literatur tersebut didapatkan melalui sumber paper dan buku. Adapaun halhal yang dapat diambil dari metode ini diantaranya adalah:[5]

a. Studi Pendahuluan : tahap ini merupakan kegiatan untuk menemukan informasi tentang obyek permasalahan yang ada. Permasalahan-persalahan yang berkembang beberapa tahun terahir dalam sebuah organisasi atau perusahaan khususnya mengenai customer churn.

b. Studi Pustaka : tahapan ini adalah tahap untuk menemukan penelitian-penelitian yang sejenis dengan penelitian ini yang nantinya dijadikan sebagai referensi dan pendukung teori dalam menyelesaikan permasalahan yang diangkat.

c. Perumusan Masalah : adapun pada tahapan selanjutnya setelah mendapatkan permasalahan utama dari obyek penelitian yang dilengkapi dasar teori dari studi pustaka yang mendukung maka masalah yang ada dapat dirumuskan dengan baik. 


\subsection{Pengumpulan Data}

Data masukan yang akan digunakan pada sistem prediksi adalah data time series bulanan dari data status pelanggan dan keluhan dan selanjutnya akan dilakukan perhitungan prediksi menggunakan metode ANFIS untuk perusahaan XYZ di Kediri. Data yang digunakan untuk prediksi merupakan data dari bulan januari 2015 sampai bulan desember 2016.

Sistem analisa yang digunakan untuk memprediksi customer churn pada perusahaan XYZ di Kediri menggunakan metode ANFIS. Untuk mencari nilai standart devisiasi dan mean, maka data di cluster menggunakan algoritma Fuzzy C Means. Kemudian dilakukan perhitungan untuk mendapatkan nilai setiap cluster. Tabel 1. merupakan data hasil clustering Fuzzy C Means yang akan diproses menggunakan perhitungan ANFIS.

Tabel 1. Clustering data Pelanggan

\begin{tabular}{|l|c|c|}
\hline \multirow{2}{*}{ Bulan } & \multicolumn{2}{|c|}{ Derajat keanggotaan } \\
\cline { 2 - 3 } & Data Status Pelanggan & Keluhan \\
\hline Januari 2015 & 0,044 & 0,956 \\
\hline Februari 2015 & 0,108 & 0,892 \\
\hline Maret 2015 & 0,13 & 0,87 \\
\hline April 2015 & 0,169 & 0,831 \\
\hline Mei 2015 & 0,529 & 0,471 \\
\hline Juni 2015 & 0,567 & 0,433 \\
\hline Juli 2015 & 0,598 & 0,0402 \\
\hline Agustus 2015 & 0,72 & 0,28 \\
\hline September 2015 & 0,73 & 0,27 \\
\hline Oktober 2015 & 0,742 & 0,258 \\
\hline November 2015 & 0,813 & 0,187 \\
\hline Desember 2015 & 0,822 & 0,178 \\
\hline Januari 2016 & 0,844 & 0,156 \\
\hline Februari 2016 & 0,849 & 0,151 \\
\hline Maret 2016 & 0,897 & 0,103 \\
\hline April 2016 & 0,914 & 0,087 \\
\hline Mei 2016 & 0,963 & 0,037 \\
\hline Juni 2016 & 0,967 & 0,033 \\
\hline Juli 2016 & 0,967 & 0,33 \\
\hline Agustus 2016 & 0,967 & 0,033 \\
\hline September 2016 & 0,967 & 0,033 \\
\hline Oktober 2016 & 0,969 & 0,031 \\
\hline November 2016 & 0.969 & 0,031 \\
\hline Desember 2016 & 0,044 & 0,956 \\
\hline
\end{tabular}

Data hasil clustering menggunakan Fuzzy C Means, selanjutnya dihitung nilai mean (a) dan standart devisiasi (c). Setelah dilakukan perhitungan, didapatkan mean dan standart devisiasi pada tabel 2 .

\begin{tabular}{|c|c|c|c|c|c|}
\hline $\mathrm{c}=$ & $\begin{array}{l}0,3716 \\
0,4550\end{array}$ & $\begin{array}{l}0,3384 \\
0,8183\end{array}$ & $a=$ & $\begin{array}{l}0,1657 \\
0,1303\end{array}$ & $\begin{array}{l}0,1175 \\
0,1083\end{array}$ \\
\hline
\end{tabular}

\subsection{Penerapan Metode ANFIS}

ANFIS adalah arsitektur yang secara fungsional sama dengan fuzzy rule base model Sugeno. Arsitektur ANFIS juga sama seperti jaringan syaraf tiruan dengan fungsi radial dengan sedikit batasan tertentu. Bisa dikatakan bahwa ANFIS adalah suatu metode yang mana dalam melakukan penyetelan aturan digunakan algoritma pembelajaran terhadap sekumpulan data. Pada ANFIS juga memungkinkan aturan-aturan untuk beradaptasi. [6]

Agar jaringan dengan fungsi basis radial ekuivalen dengan fuzzy berbasis aturan model sugeno orde 1 ini, diperlukan :

1) Aturan-aturan harus memiliki metode agegrasi yang sama untuk menghasilkan semua outputnya. 
2) Jumlah fungsi aktivasi harus sama dengan jumlah aturan fuzzy (IF - THEN).

3) Jika ada beberapa input pada basis aturannya, maka tiap-tiap fungsi aktivasi harus sama dengan fungsi keanggotaan tiap - tiap input-nya.

4) Fungsi aktivasi dan aturan-aturan fuzzy harus memiliki fungsi yang sama untuk neuron-neuron dan aturan-aturan yang ada di sisi output-nya.

Berikut merupakan arsitektur jaringan ANFIS :

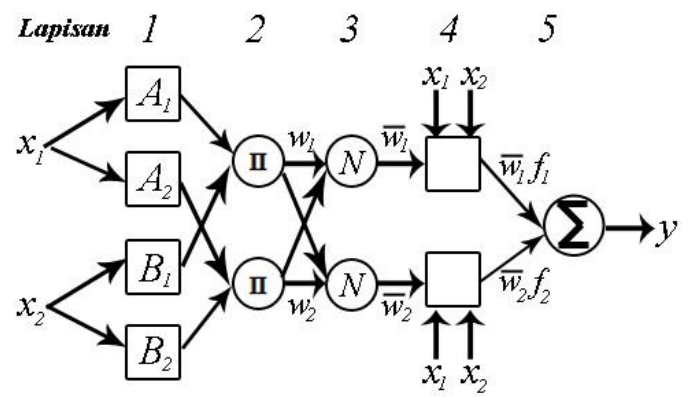

Gambar 2. Arsitektur Jaringan ANFIS [6]

Arsitektur jaringan ANFIS (Gambar 2) terdiri dari lapisan berikut :

1) Tiap-tiap neuron i pada lapisan pertama adaptif terhadap parameter suatu fungsi aktivasi. Output dari tiap neuron berupa derajat keanggotaan yang diberikan oleh fungsi keanggotaan input, yaitu: $\alpha_{\mathrm{A} 1}\left(\mathrm{X}_{1}\right), \alpha_{\mathrm{B} 1}\left(\mathrm{X}_{2}\right), \alpha_{\mathrm{A} 2}\left(\mathrm{X}_{1}\right)$, atau $\alpha_{\mathrm{B} 2}\left(\mathrm{X}_{2}\right)$.

2) Tiap-tiap neuron pada lapisan ke dua berupa neuron tetap yang outputnya adalah hasil dari masukkan. Biasanya digunakan operator AND. Tiap-tiap node merepresentasikan $\alpha$ predikat dari aturan ke-i.

3) Tiap-tiap neuron pada lapisan ke tiga berupa node tetap yang merupakan hasil perhitungan rasio dari $\alpha$ predikat (w), dari aturan ke-1 terhdap jumlah dari keseluruhan $\alpha$ predikat.

$\mathrm{W}_{\mathrm{i}} \overline{=} \frac{\mathrm{wi}}{\mathrm{w} 1+\mathrm{w} 2}$, dengan $\mathrm{i}=1,2$

Hasil ini dikenal dengan nama normalised firing strength.

4) Tiap-tiap neuron pada lapisan ke empat merupakan node adaptif terhadap suatu output.

$$
\overline{\mathrm{Wi}} \mathrm{Yi}=\mathrm{Wi}\left(\mathrm{C}_{\mathrm{i} 1} \mathrm{X}_{1}+\mathrm{C}_{\mathrm{i} 2} \mathrm{X}_{2}+\mathrm{C}_{\mathrm{i} 0}\right) \text {; dengan } \mathrm{i}=1,2
$$

Dengan Wi adalah normalised firing strength pada lapisan ke tiga dan $\{\mathrm{Ci} 1, \mathrm{Ci} 2, \mathrm{Ci} 3\}$ adalah parameter-parameter pada neuron tersebut. Parameter-parameter pada lapisan tersebut disebut dengan nama consequent parameter.

5) Tiap-tiap neuron pada lapisan ke lima adalah node tetap yang merupakan jumlahan dari semua masukkan.

Algoritma hybrid akan mengatur parameter-parameter Cij secara maju (forward) dan akan mengatur parameter-parameter $\{$ ai, bi, ci) secara mundur (backward). Pada langkah maju, input jaringan akan merambat maju sampai pada lapisan ke empat, dimana paraameter-paarameter $\mathrm{Cij}$ akan diidentifikasi dengan metode least squares estimator (LSE). Sedangkan langkah mundur, error sinyal akan merambat mundur dan parameter-parameter (ai, bi, ci) akan diperbaiki dengan menggunakan metode gradient-descentc(GD). [7]

\subsubsection{Langkah Maju Dengan Metode LSE}

Dari arsitektur ANFIS, bila parameter tetap maka keluaran keseluruhan dapat dinyatakan dengan kombinasi linear dari parameter konsekuensi. [7]

$$
\mathrm{f}=\mathrm{f} 2=\frac{W 1}{W 1+W 2} f 1+\frac{W 2}{W 1+W 2}
$$




\subsubsection{Langkah Balik Dengan Metode GD}

Terdapat beberapa metode penurunan gradient dalam masalah optimasi, antara lain : [7]

1) Metode penurunan tercuram (Steepest Descent, SD)

2) Metode Newton yang terdiri atas Newton klasik, Newton termodifikasi, dan Quasi Newton.

3) Metode Conjugate Gradient.

\section{HASIL DAN PEMBAHASAN}

Setelah melakukan pembagian (clustering) data menggunakan metode Fuzzy C Means dan mendapatkan nilai Standar deviasi dan Mean, selanjutnya kita akan mencari nilai inferensi dengan menggunakan metode Adapotive Neuro Fuzzy Inference System (ANFIS). Pada perhitungan metode ANFIS ini akan dilakukan perhitungan pada setiap lapisannya. Sistem inferensi fuzzy yang diterapkan adalah inferensi fuzzy model Sugeno.

\subsection{Lapisan Pertama (Proses Fuzifikasi)}

Pada lapisan pertama terjadi proses fuzifikasi. Proses ini adalah untuk memetakan inputan data kedalam himpunan fuzzy. Dalam proses ini akan dilakukan perhitungan fungsi keanggotaan fuzzy untuk mentransformasi masukan himpunan klasik ke derajat tertentu. Fungsi keanggotaan yang digunakan adalah IV-15 jenis Generalized-Bell dimana pada fungsi keanggotaan ini terdapat dua parameter yaitu mean dan standar deviasi. Data output lapisan pertama ditunjukkan dalam tabel 2.

Tabel 2.Data Output Lapisan Pertama

\begin{tabular}{|l|l|l|l|l|}
\hline \multicolumn{5}{|c}{ Derajat keanggotaan } \\
\hline Bulan & $\mu a 1$ & $\mu a 2$ & $\mu b 1$ & $\mu b 2$ \\
\hline Januari 2015 & 5,4363 & 0,7322 & 5,6331 & 8,9807 \\
\hline Februari 2015 & 0,2616 & 0,3087 & 0,5257 & 0,0796 \\
\hline Maret 2015 & 0,2616 & 0,3087 & 0,9998 & 0,0488 \\
\hline April 2015 & 0,2616 & 0,3087 & 0,0661 & 0,8888 \\
\hline Mei 2015 & 0,3586 & 0,1543 & 0,9998 & 0,0488 \\
\hline Juni 2015 & 0,3586 & 0,1543 & 0,9949 & 0,0469 \\
\hline Juli 2015 & 0,3873 & 0,5208 & 0,0345 & 0,3687 \\
\hline Agustus 2015 & 0,4032 & 0,1729 & 0,2195 & 0,1495 \\
\hline September 2015 & 0,4631 & 0,6529 & 0,622 & 0,0722 \\
\hline Oktober 2015 & 0,4919 & 0,7015 & 0,5722 & 0,0757 \\
\hline November 2015 & 0,5779 & 0,2511 & 0,2412 & 0,0242 \\
\hline Desember 2015 & 0,6132 & 0,2686 & 0,2536 & 0,1315 \\
\hline Januari 2016 & 0,6132 & 0,2686 & 9673 & 0,0529 \\
\hline Februari 2016 & 0,8171 & 0,9985 & 0,9761 & 0,0451 \\
\hline Maret 2016 & 0,8544 & 0,9869 & 0,5402 & 0,0328 \\
\hline April 2016 & 0,8786 & 0,4468 & 0,5402 & 0,0328 \\
\hline Mei 2016 & 0,8895 & 0,9645 & 0,5402 & 0,0328 \\
\hline Juni 2016 & 0,8895 & 0,9645 & 0,5402 & 0,0328 \\
\hline & & & & \\
\hline & & & & \\
\hline & & & & \\
\hline & & & & \\
\hline
\end{tabular}




\begin{tabular}{|l|l|l|l|l|}
\hline Juli 2016 & 0,8895 & 0,9645 & 0,5402 & 0,0328 \\
\hline Agustus 2016 & 0,8895 & 0,9645 & 0,5257 & 0,0796 \\
\hline September 2016 & 0,8895 & 0,9645 & 0,0466 & 0,8144 \\
\hline Oktober 2016 & 0,8895 & 0,9645 & 0,5402 & 0,0328 \\
\hline November 2016 & 0,9645 & 0,5621 & 0,1245 & 0,2928 \\
\hline Desember 2016 & 0,9649 & 0,5621 & 0,069 & 0,8341 \\
\hline
\end{tabular}

\subsection{Lapisan Kedua dan Lapisan Ketiga}

Output dari lapisan kedua adalah hasil perkalian dari semua sinyal yang masuk. Masing-masing keluaran simpul menyatakan derajad pengaktifan dari aturan fuzzy. $w 1=\mu A 1(\mu B 1)$. dan, $w 2=$ $\mu A 2(\mu B 2)$.

Pada lapisan ke tiga Setiap node pada lapisan ini adalah node nonadaptif yang menampilkan fungsi derajat pengaktifan ternomalisasi (normalized firing strength) yaitu membagi wi dengan jumlah total $\hat{\mathrm{W}}_{1}$ dan $\hat{\mathrm{W}}_{2}$. Data output lapisan pertama ditunjukkan dalam tabel 3.

Tabel 3. Output Lapisan Kedua Dan Output Lapisan Ketiga

\begin{tabular}{|l|l|l|l|l|}
\hline \multirow{2}{*}{ Bulan } & \multicolumn{2}{|c|}{ Output lapisan ke dua } & \multicolumn{2}{c|}{ Output lapisan ke tiga } \\
\cline { 2 - 5 } & $\mathrm{W} 1$ & \multicolumn{1}{|c|}{$\mathrm{W} 2$} & $\hat{\mathrm{W}} 1$ & $\hat{\mathrm{W}} 2$ \\
\hline Januari 2015 & 0,0134 & 0,192 & 0,0651 & 0,9349 \\
\hline Februari 2015 & 0,0173 & 0,0142 & 0,0593 & 0,9407 \\
\hline Maret 2015 & 0,0415 & 0,7855 & 0,0501 & 0,9499 \\
\hline April 2015 & 0,0445 & 0,6045 & 0,0685 & 0,9315 \\
\hline Mei 2015 & 0,0666 & 0,4688 & 0,1243 & 0,8757 \\
\hline Juni 2015 & 0,0885 & 0,0258 & 0,774 & 0,226 \\
\hline Juli 2015 & 0,1201 & 0,1646 & 0,4219 & 0,5781 \\
\hline Agustus 2015 & 0,1375 & 0,0246 & 0,8484 & 0,1516 \\
\hline September 2015 & 0,1394 & 0,0061 & 0,9582 & 0,0418 \\
\hline Oktober 2015 & 0,1555 & 0,0353 & 0,8149 & 0,1851 \\
\hline November 2015 & 0,2615 & 0,0151 & 0,9455 & 0,0545 \\
\hline Desember 2015 & 0,2815 & 0,0531 & 0,8413 & 0,1587 \\
\hline Januari 2016 & 0,288 & 0,0471 & 0,8594 & 0,1406 \\
\hline Februari 2016 & 0,3568 & 0,0072 & 0,9801 & 0,0199 \\
\hline Maret 2016 & 0,3585 & 0,0075 & 0,9794 & 0,0206 \\
\hline April 2016 & 0,4615 & 0,0324 & 0,9345 & 0,0655 \\
\hline Mei 2016 & 0,4676 & 0,0768 & 0,859 & 0,141 \\
\hline Juni 2016 & 0,4746 & 0,0147 & 0,97 & 0,03 \\
\hline Juli 2016 & 0,4805 & 0,0316 & 0,9382 & 0,0618 \\
\hline Agustus 2016 & 0,4805 & 0,0316 & 0,9382 & 0,0618 \\
\hline September 2016 & 0,4805 & 0,0316 & 0,9382 & 0,0618 \\
\hline Oktober 2016 & 0,4805 & 0,0316 & 0,9382 & 0,0618 \\
\hline November 2016 & 0,5931 & 0,7855 & 0,9766 & 0,0234 \\
\hline Desember 2016 & 0,7976 & 0,045 & 0,9466 & 0,0534 \\
\hline
\end{tabular}

\subsection{Lapisan Keempat (Proses Defuzifikasi)}

Pada lapisan ini dilakukan perhitungan mengubah hasil fuzzy kebentuk menjadi himpunan klasik (crisp). Pada lapisan ini dilakukan perhitungan LSE untuk mendapatkan nilai parameter koefisien.

\subsection{Lapisan Kelima}

Pada lapisan ini hanya ada satu node tetap yang fungsinya untuk menjumlahkan semua masukan yang berasal dari lapisan keempat. 
Tabel 4. Output Lapisan Kelima

\begin{tabular}{|l|c|c|}
\hline \multicolumn{1}{|c|}{ Bulan } & Data Masukan & Hasil Prediksi \\
\hline Januari 2015 & 360 & 301 \\
\hline Februari 2015 & 480 & 350 \\
\hline Maret 2015 & 490 & 253 \\
\hline April 2015 & 500 & 338 \\
\hline Mei 2015 & 600 & 349 \\
\hline Juni 2015 & 660 & 499 \\
\hline Juli 2015 & 660 & 499 \\
\hline Agustus 2015 & 660 & 360 \\
\hline September 2015 & 660 & 499 \\
\hline Oktober 2015 & 670 & 512 \\
\hline November 2015 & 730 & 412 \\
\hline Desember 2015 & 750 & 379 \\
\hline Januari 2016 & 770 & 549 \\
\hline Februari 2016 & 780 & 405 \\
\hline Maret 2016 & 880 & 566 \\
\hline April 2016 & 980 & 675 \\
\hline Mei 2016 & 980 & 679 \\
\hline Juni 2016 & 990 & 534 \\
\hline Juli 2016 & 990 & 752 \\
\hline Agustus 2016 & 1100 & 791 \\
\hline September 2016 & 1110 & 574 \\
\hline Oktober 2016 & 1270 & 657 \\
\hline November 2016 & 1300 & 691 \\
\hline Desember 2016 & 1430 & 887 \\
\hline
\end{tabular}

\subsection{Evaluasi}

Setelah mendapatkan hasil \% error prediksi customer churn dengan menggunakan faktor data status pelanggan dan data keluhan, maka dilakukan perhitungan error dengan pengurangan data sebenarnya dengan hasil peramalan.

Tabel 5. Perbandingan nilai error

\begin{tabular}{|l|c|}
\hline \multicolumn{1}{|c|}{ Bulan } & Error \% \\
\hline Juli 2016 & $9,5 \%$ \\
\hline Agustus 2016 & $13,7 \%$ \\
\hline September 2016 & $8,2 \%$ \\
\hline Oktober 2016 & $6,3 \%$ \\
\hline November 2016 & $7,8 \%$ \\
\hline Desember 2016 & $4,4 \%$ \\
\hline
\end{tabular}

\section{SIMPULAN}

Berdasarkan penelitian yang telah dilakukan, dengan menggunakan metode ANFIS dapat membantu perusahaan XYZ untuk mengetahui prediksi pelanggan yang melakukan churn. Dengan mengetahui prediksi pelanggan yang melakukan churn, maka akan memberikan keuntungan untuk manajemen, khususnya divisi Customer Relationship Management (CRM), dapat menciptakan promosi yang bertujuan untuk meningkatkan loyalitas pelanggan dan meningkatkan strategi penjualan untuk mendapatkan pelanggan baru dan melakukan retensi pelanggan. Pelatihan dan pengujian ANFIS untuk semua produk menghasilkan perbandingan nilai error rata-rata pelatihan sebesar $8,316 \%$.

\section{SARAN}

Saran yang dapat diberikan bagi pengembangan penelitian di masa mendatang terkait prediksi customer churn dengan menambah parameter agar menghasilkan nilai prediksi yang lebih baik lagi. 


\section{DAFTAR PUSTAKA}

[1] Fikrieabdillah. 2016. Penggunaan Deep Learning untuk Prediksi Churn pada Jaringan Telekomunikasi Mobile.e-Proceeding of Engineering : Vol.3, No.2.

[2] Herawati, Meyrina, Imam Mukhlash dan Inu L. Wibowo. 2016. Prediksi Customer Churn Menggunakan Algoritma Fuzzy Iterative Dichotomiser 3. J. Math. and It s Appl : Vol . 13, No. 1.

[3] Kusrini dan Emha Taufiq Lutfi. 2009. Algoritma Data Mining. Yogyakarta : Andi Offset

[4] Olivia, Cici, Indwiarti dan Yulian Sibaroni. 2015. Analisis Prediksi Churn Menggunakan Metode Logistic Regression Dan Algoritma Decision Tree. E-Proceeding Of Engineering : Vol.2, No.2.

[5] Arifin, Muhammad. 2015. Ig-Knn Untuk Prediksi Customer Churn Telekomunikasi. Jurnal Simetris, Vol 6 No.1.

[6] Jang, S.; Sun T., dan Mizutani E. (1997). Neuro-Fuzzy and Soft Computing A Computational Approach to Learning and Machine intelligence, Prentice Hall, Inc. ISBN 0132610663.

[7] Kusumadewi, Sri dan Sri Hartati. 2010. Neuro-Fuzzy Integrasi Sistem Fuzzy \& Jaringan Syaraf. Yogyakarta : Graha Ilmu. 